\title{
Design and Development of a Virtual Platform Destined to Store Ancestral Botanic Knowledge
}

\author{
Gloria Flores-Fuentes ${ }^{1}$, Yadira Navarro ${ }^{1}$, Emilio Soto ${ }^{1}$, Eva Hortensia Cházaro Arellano ${ }^{2}$ \\ ${ }^{1}$ Benemérita Universidad Autónoma de Puebla, México \\ ${ }^{2}$ Universidad de las Américas Puebla, México
}

\begin{abstract}
Presently, indigenous knowledge is recognized as valuable in the development of the indigenous peoples. Unfortunately, it runs the risk of disappearing for various reasons and it is of dire need to win it back and preserve it and one way to do so is through the tools the ICT give us. In this paper a proposal is made to create a virtual community, referred to as $C V$ (comunidad virtual), that allows the creation of digital lockers where ancestral wisdom can be stored.
\end{abstract}

\section{Introduction}

Throughout their existence indigenous people have accumulated an amount of knowledge derived from their interaction with nature and the way they understand and believe things to be divine. The transmission of this wisdom is through storytelling to the passing generations. The importance of this knowledge resides, amongst other things, in how fundamental they are in giving cultural identity to the people and how they help them preserve vital natural resources [1]. However, this wisdom tends to dissipate [1], [2], and because of its importance it is necessary to store it and doing so in a digital format also makes the indigenous people participants of the digital era. Some studies prove that it is possible to preserve their knowledge by use of TIC allowing the people to participate in using them[3], [4]. What follows is a proposal to retrieve, preserve, and spread the ancestral knowledge of the tribes regarding medicinal plants with the natives' participation in a $\mathrm{CV}$ modeled after what some authors refer to as "cultural logic" [5].

This is part of a project with the goal of creating a model to strengthen the preservation and the value of ancestral botanic knowledge within an indigenous community in the state of Puebla with the use of a virtual dynamic platform. As a distinctive trait of the collectivity these indigenous communities share we propose a Virtual Community that will add to the cultural logic the community holds in respect.

\section{Related projects}

Faced with the erosion of ancestral wisdom and cultural traditions, some countries have taken initiative in giving diverse electronical resources for the sake of indigenous wisdom. Some of these initiatives and other projects as well, take place in various countries.

The TKDL - The Traditional Knowledge Digital Library of India is a Project designed to digitalize the information regarding medicinal plants of the area. This was the initiative of the NISCAIR and the medicine and homeopathy department of India in 2001. At first it focused on digitalization of the wisdom coming from Ayurveda, and later other systems of traditional and alternative medicine. The software used allows the information to be present in many languages. (English, German, French, Spanish and Japanese)

IKM - Indigenous Knowledge Management is a tool designed by the University of Queensland's engineering and technology department. The software was developed to allow indigenous communities to protect their culture and wisdom through digitalization. The tools of this software lets authorized member of the communities to systemize and control the content. It also grants privileges to those authorized to define the rights, the access, and retrieval of these resources. Granting control of the content to authorized members serves the purpose of respecting the laws regarding the knowledge and what is considered sacred and divine. It also prevents the wrong use of the indigenous heritage in any way and it guarantees the proper attribution because it is the same community that describes their knowledge in their own words.

E-TORO - Designed to recollect, organize, store, and allow access to knowledge. This tool is the product of investigation done by Zaman and Yeo [6], and the Long Lamai community of Malasia collaborated. Documentation consists of three steps: the first step has the young members of the community walk the woods in Company of the elders so they can be taught about plants; the second step is verifying the information gathered with the community; and the third step uses digital systems to manipulate this information. As part of the results, the elders have shown great use of the eTORO tool and they understand the importance of storing the information. However some difficulties have been reported, like the process of negotiation and discussion with the members of the community, 
which was lengthy in time. Developing this project also interfered with the agricultural activities of the people and so finding the time when both investigators and members of the community could work was difficult.

Research done in the community of Herero in Namibia [7] studies the interaction of members through recording and interpreting videos that are later used to design digital systems compatible with the way the Herero increases and transmits their concept and knowledge in botanic. The authors make a strong emphasis in what is known as "cultural logic". This is fundamental in the way wisdom is transmitted by the Herero.

In Costa Rica, Brenes made a study with the young members of the Cabecar indigenous group [8], and they created interactive material to promote their culture and language. The conclusion of this research is that the introduction of TIC and digital methods in indigenous communities must be done from a mutual sharing of knowledge. This in turn helps them understand our culture better.

Slavsky [9] realized after research that creating a Web page, with the traditional wisdom of the Mapuche people (from southern Chile) helped in finding and retrieving the information regarding culture and identity easier. The web page has been getting more and more visits and the author assures that the design itself helps re-build the social schemes.

The initiatives and research seen at the moment show the effort that is being put in preserving the indigenous knowledge. Some focus on the development of tools and technological devices needed, while others focus on the methodology that comes with the necessities of the communities. The present investigation takes focus on both the development of tools and the methodology that follows accordingly to the indigenous community.

\section{Background}

\subsection{Indigenous knowledge}

This has several meanings; however, in this paper we take what the Comisión Nacional para el Desarrollo de los Pueblos Indígenas (CDI) says about indigenous knowledge: "the gathering of intellectual and practical truths about the world inherited by the elders and passed through generations verbally or symbolically. This wisdom is gathered throughout time with the interaction of men and nature. It is not written, and it is not defined, and rather related to spirituality and nature, everything meaningful to the people." [1]. This definition is used and clarified because of the polysemy Indigenous knowledge has. This definition is one the indigenous people gave.

\subsection{Problem of the investigation}

Indigenous communities in Mexico have traditions and wisdom that, besides being part of their cultural identity, may serve greater goods. In present day however, due to globalization and the rapid development of TIC, some of this diversity in culture is fading, and this puts all the indigenous wisdom in danger of becoming extinct, making the communities face a loss of identity.

According to several investigations [10]-[12], ancestral botanical knowledge is eroding. Benz found that if the communities kept their language their knowledge they keep is more diverse and the opposite occurs in communities where they have adopted a new language and forgotten theirs [11]. Another observation was how the younger generations seem less and less in touch with that part of their culture.

Forums have been made by the CDI that show the opinion of the indigenous people as to their ancestral wisdom. The biggest part here is explaining the several mechanisms designed to protect this wisdom and all other cultural aspects rooting from it. This forum took place in 2008 through 2010 and 1,418 indigenous people from 46 different linguistic groups took part in it.

The results show also that the indigenous people are aware of the importance their ancestral wisdom has in keeping a cultural identity and preserving natural resources. They admit that their knowledge is being lost to globalization, industrialization, discrimination, migration and stigmas surrounding them.

Other polls done by the CDI confirm what the indigenous people say is the problem to their knowledge being threatened [1], [13], [14]. On the other hand, ancestral wisdom seems to be a key in preserving biodiversity.

The loss of all the ancestral knowledge is therefore a problem that grows with time and finding ways to preserve it and to stop the progressive erosion is what ICT are being proposed for.

For this project we take into that ancestral botanic knowledge is a dynamic system where its transmission and endurance between indigenous people depends on oral tradition and has depend on it for several years and thus, we propose recording all the information on audiotapes or videos This way of storing oral tradition is the most adequate and it will be done by the members of the indigenous community so as to not take away from them the custom of storytelling and verbally transmitting their wisdom. Because of the technology necessary for recording the information, the high school students of the community will be in charge of doing it. 


\subsection{Context of the community}

The municipality of Teopantlán is found west in the state of Puebla in Mexico. Even in relative nearness to semi-urban areas, the population in this municipality is considered as an indigenous community. Around $70.7 \%$ of anyone over 5 years of age speaks the native tongue [15]. Most of the inhabitants work the crop fields and their political organization is based on the type of service one gives to the entire community and are defined, as follows: "Ideally it is a stair like system through which citizens use communal force to organize activities outside of the community to link with external institutions and other communities" [16].

Within the community the most noticeable system of charges is that of the stewardship, which involves no more than organizing and overseeing the religious festivities of the community, young and old members are bound to participle in the religious activities. However, holding a stewardship means a great honor for the members of the town and they oversee everything with visible pride, and so the rest of the community supports them all the way. We can tell too that, with the passing of time, this practice and several others, as well as the mother tongue, are fading away.

Crafts like weaving palm fiber to make tenates (a sort of bowl to transport food), petates (rugs) and aventadores (a type of fan used to start fire) are made by a few families of the community and so, the prices of such products is not stable and it involves a very long process making them. Figure 1 shows a woman weaving palm.

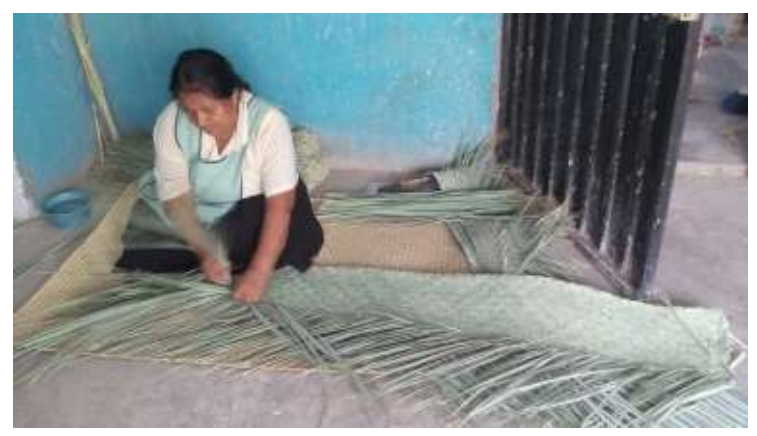

Figure 1. Teopantlán woman weaving palm

Agriculture is very prominent among the Teopantlán but their main source of economic support comes from remittance sent from family members that have migrated to the United States. The community has internet connectivity through a Communitarian Digital Center and sometimes through their phone services. As a result of the constant and heavy migration towards the United States the uses of electronic devices like cell phones, tablets, portable computers etc. This is because their relatives are in more direct contact with them and thus encourage buying these items and the money they send can cover those expenses.

As in all communities, there is a generational difference between the people who emigrate. First, all adults old enough to hold a job leave, and then the young members that have finished nine years of school and only when steady job is held the rest of the family is called to move away to the United States, first the wife and then the rest of the extended family.. When people leave and leave their kids in the community, they trust their education and upbringing to their parents, this helps the kid learn the native tongue, reasons for which bilingual students are found in the schools.

Another observation on people that have moved away at a young age, especially at the northern border, is they come back with a completely changes set of mind and they bring with them the common practices of the places they worked. They dress differently, sport tattoos and talk about all the new things being done in the north, and so far there is no visible rejection towards it form the other members of the community.

Within the community there are elementary schools and high schools. The students from high school have certain knowledge of the usage of TIC, for example, on an explicatory poll most of the students own a Smartphone and although they basically used them for texting and WhatsApp, they are familiar with the other applications such as the camera, music reproduction, games and calculator.

They also have knowledge of computers and can surf and identify the components of the hardware. They can work with programs like Cmaptools, to visually organize information, and interact with the virtual platform Edmodo as well as with other interactive media like PowerPoint presentations and YouTube videos. So we can establish they use smartphones, mostly for chatting, and the computer to do their homework

\subsection{Virtual Community}

The virtual community (VC) is design so the high school students of the community can recollect and store all the knowledge of medicinal plants in a digital format. The activities, forums and the digital library is based on the Pedagogical Native Model [17]. For now our intention is to have the students form the $\mathrm{VC}$ and for the rest of the community to visit the digital library. The VC will include spaces and debate tables where the students can discuss about the use of plants and how they can improve the library. All the information will be stored in both Spanish and Nahuatl, the mother tongue.

The entire design of VC is modeled after what is known as "cultural logic". This makes an allusion to the ways knowledge is traditionally transferred, like pedagogy, and the people's everyday life. For this, 
the platform works through PNM (pedagogical native model). Another important aspects as to why the VC was chosen is because of its collective trait, which is present in the indigenous community lifestyle [17]. These two aspects, the PNM and the collective trait, give a distinctive tone to the design of the virtual community.

In the end, the VC is proposed to preserve, store, and spread the ancestral knowledge on botanic and all this done by the members of the communities whose identity is at risk. The sense of value refers to how useful this tool was in helping the community

\subsection{The Pedagogical Native Model}

The PNM is based on Native wisdom, and it has been systematized by Cházaro [17]. In her work she recognizes 4 dimensions that detail the way indigenous people teach the generations to become individuals with values, with a deep respect for nature. The four dimensions are:

3.5.1. Pacha Dimension. This dimensional relation implies a living communication between the three collectives Maker-Human-Mother Earth, marked with a religious respect.

Earth is viewed as sacred, and in that knowledge the mind and spirit are reformed. To quote the author "in this dimension, the native learns to consider earth as sacred, and to identify as part of the whole universe. All these values are then transferred and they become a part of the lifestyle of the community, and they extend not only to other people but to every living being. Amongst the things learned from Pacha dimension we count peaceful coexistence, protection of nature and recognition of divinity".

3.5.2 Community Dimension: This dimension comprehends the categories of earth, service, ceremony and work. One learns from nature, from living beings, from human interaction, productive and sacred work. Our senses are used and so we learn to be with others, to serve, and the body learns through dances and songs.

"Sometimes is always learnt, every moment of every living being, every relation to nature. We learn from divine will and earth. We learn by productive work with other people. We learn thus to live guided by our hearts and beyond our minds. We learn to share, to serve and only then do we become powerful" says the author.

3.5.3. Nechnonotza Manicmati Dimension (I am told in order to know). This one is the basis of the entire model of teaching, the elders are the ones in charge of transmitting the knowledge that comes from years of experience and they do so verbally.

About the elders, the author said "native families have them in the esteem of teachers, healers and wise spiritual guides; people with great sensitivity and heart; sharing and in touch with Pacha and communal life and their ways of learning are more authentic than those the rest of the people have. As teachers of Nechonotza Manicamati, they spend their time in ceremonies, prayers, plowing, and overseeing the whole community gets along well".

3.5.4. Territorial Space Dimension. This dimension explains how wisdom in turn teaches us to share, and so the wisdom indigenous people have they want to share with foreigners so they may learn the way they, the native, do things.

To share what is proper of the native world to everyone else without imposing looks, in the most pure fashion possible, without fear of being judged by the "western lifestyle", to share without holding back.

The Pedagogical Native Model tells how integral human beings with values are made, and how deep a bond they share and respect they have with nature. Figure 2 shows how the PNM works [17].

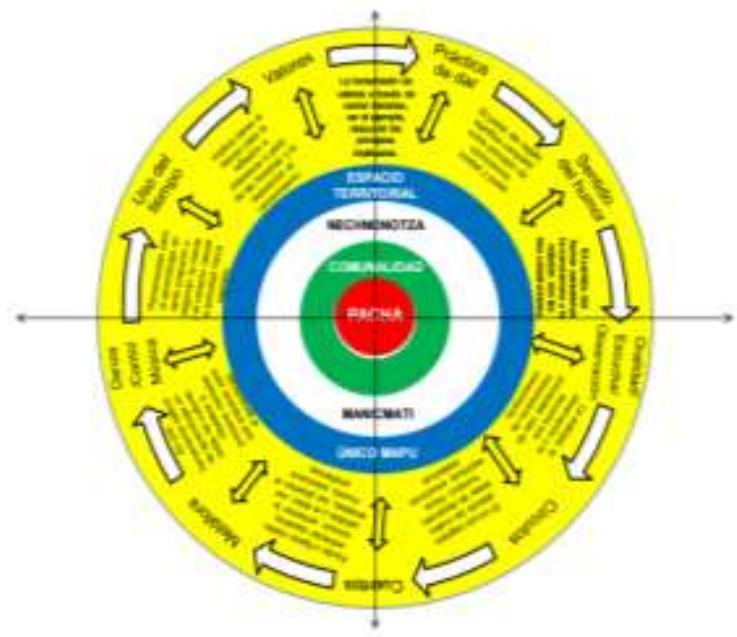

Figure 2. Pedagogical Native Model based on wisdom

The graph details the elements of the model: the dimensions as circles that include or exclude each other, the strategies and activities linked to learning are shown with White arrows behind them, and the interaction and learning are happening at all times, in every direction, as shown by the double headed arrows.

In this study we propose the PNM to preserve the indigenous knowledge, and the construction of a VC, in a way that the pedagogical model has cultural relevance to the members of the community and avoid any loss of interest [13]. Amongst its perspectives the VC works theories like socialconstructivism, and online learning [14]. In this project the innovation is the use of PNM in making the virtual community.

Just as stated by Bidwell in their investigation with the Herero people of Namibia, success of the 
project relies on the pedagogy through which the knowledge of plants is transmitted and remains a key fact of cultural logic [7]. In this study, PNM forms part of the cultural logic of the community of Teopantlán.

\section{Proposed methodology}

The knowledge about the use of medicinal plants will be recollected by the younger members of the indigenous community through questioning and multimedia productions such as videos and sound recordings, furthermore they will begin making a virtual community that will hold debates and forums as to the many uses plants of medicinal nature have. At the same time the $\mathrm{VC}$ is being built, a digital database will be made with the progressive entries of information gathered.

The starting point of recollecting and gathering information as well as transforming it to a digital format is the school, but making a database so vast will involve the participation of all the members of the community.

So far, a test of the instrument (a questionnaire) used to gather information of ancestral lore, has been done in two parts. This questionnaire or interview asks about the knowledge of plants that can serve medicinal purposes and how familiar are the members of the community with them. Initially the questions were 21 but thanks to the positive response and interaction with the participants, some concepts were honed. Because it is a semi structured interview or questionnaire, we identified key questions that allow the participant to elaborate on subjects relevant to the investigation

In the second part the final instrument was synthetized in 5 questions regarding medicinal plants. The questionnaire used was this one:

- Do you know any medicinal plants? Which? What do they cure?

- How are they prepared?

- How are they taken?

- Who taught you how to use them?

- Do you teach others to use them?

During the test most of the elders agreed that the younger members are less interested in certain tradition, such as learning the medicinal plants around them because they deem it as old-school. Some expressed their feelings towards all that modernization has brought to their community and especially to the food made from the local plants.

"People here rarely eat plants, we do in our home but the kids these days don't want to anymore. My wife and I we eat plants, but our kids don't like to, they still eat them though, when we make them"

The elders answering the poll all agreed that their parents and grandparents knew even more than they did and that even if they spend a long hours' working in the crop fields it was their ancestors that spent more time in it and therefore knew the medicinal plants even better. They all use medicinal plants and Mister Pedro said:

"Temazcal is what is used most around here to cure any condition. Every three days people bath and attend temazcales and they get better, like after childbirth, they bind their hips and taking regular baths and temazcal gets them stronger, if they don't bath or take temazcal they get sick, it is the vapor of the temazcal that helps heal wounds. Other wounds are treated with arnica, arnica is good as well, just rub some on your wounds and attend a temazcal and everything gets better."

Temazcal is a type of sweet lodge which originates with pre-Hispanic indigenous peoples in Mesoamerica. It is used for healing the sick, improving health, and for women to give birth. It is currently being recovered by all sectors of society in Mexico and Central America and is used as a cleansing of mind, body and spirit.

With the test done it was possible to adapt and perfect the instrument for gathering ancestral knowledge that will be used by the young participants, it also allowed exploration of what the people know about their culture and their surroundings. One of the most shocking things was experiencing first hands what the elders felt about their wisdom being eroded. Some elders explained how they no longer use some plants because they no longer know their virtues. They explained that the way they understand the native tongue is also lesser than the way their ancestors understood it and that at present some of the young members understand but no longer try to speak the language. The exceptions are the kids whose parents moved and so were raised by their grandparents.

\subsection{Consult and participations forums}

It is essential for the community to participate in the construction of the VC. So far leaders of the communities have been contacted, for example those who have held a civil charge or a religious one in the community. These leaders have manifested their support in making this project come true and are willing to participate to actively be a part of it. With this we guarantee a sense of meaning to the members 
of their community [18]. The next part of the poll has to be made with the parents of those who will participate in building the $\mathrm{VC}$ so everyone in the community is informed about the project in its entirety. During the test all of the elders interviewed showed enthusiasm when they were told their wisdom would be stored and preserved digitally, stating it was all part of their identity.

\subsection{ICT appropriation and making content}

Designing a Virtual Community along with the methodology proposed before makes the inclusion of the digital era to the young members of the community. They will be in charge of creating the material that will become their cultural legacy. Their ancestral knowledge, faced with the risk of disappearing, has a chance at surviving with digital aid. This and the inclusion of TIC is what gives them the chance to create content [9].

This platform is then a space for people to spread the cultural components of their community. Workshops will take place to guide the students on the task of creating interactive applications with the content that can later be stored in the platform.

The content of the digital database the high scholars will create will depend on their criteria. For example, the polls that are made to recollect this info will then be turned into videos or audios. Some workshops will be held where the students are taught how to use the computers and all the programs in the most complete way so the database can be complete in the form of a platform. The workshops are also designed under the scope of PNM, where debate circles are made. With these propositions the focus of PNM will point out to the participants their trust, freedom of expression, and freedom to make suggestions that allow the Virtual Community to enrich the same workshop. During said workshop the PNM will be first put to test.

\subsection{Virtual discussion forums}

The discussion forums are destined for debates amongst the participants over topics like the use of medicinal plants and the way the information should be transcribed in the VC. It will also serve the purpose of social activity and interaction with themes completely outside indigenous wisdom.

Additionally to the debate forums, activities linked to PNM are contemplated, such as recollection of myths and stories that have been transmitted orally.

The young members will have to spend time in close contact with nature and for this, the activity of plant mapping is proposed. In this case it will be the elders teaching them where they can find specific plants of medicinal use. This helps create more information to be stored and also to strengthen bonds between elders and youngsters, and youngsters and their surrounding nature.

The database will consist of information on medicinal plants, where to find them, and stories and myths relevant to the lore.

\subsection{Digital database}

The digital database will consist of multimedia productions made by the young members of the indigenous community, and the content will be about the use of medicinal plants as well as stories and myths that are included in the identity of the community. The database will be bilingual, for the speakers of Nahuatl and Spanish as shown in figure 3.

The intention of making a database in Nahuatl is to promote the use of the mother tongue. In a way it also promotes the cultural identity of the community.

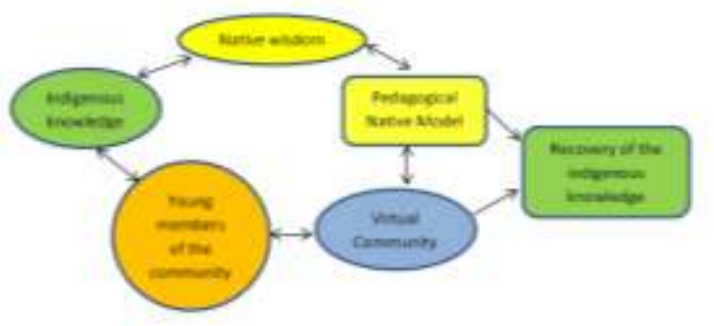

Figure 3. Graph of the proposition

The digital database will be built through a wiki found on the Virtual Community, and on this wiki a web page will be made for every plant recorded; on this page all the information relevant to the plant will be transcribed in a way it can be safely stored and efficiently retrieved such as videos or audios of stories, myths, or legends that can link the plant to its medicinal uses. During the forums or debate circles of the virtual community the format of all the information will be discussed.

One thing to point out is that the people from this community will be the only ones with access to the virtual community, making them the sole editors and writers, as well as the only public. Only after they decide the virtual community is ready for any person from the outside to visit it, will it be made open to the general public.

Based on our research work we hope to bind the gap that separates the knowledge of elders and that of younger members of the community and to analyze the interaction the indigenous people have with the platform to determine if a virtual community based on the Pedagogical Native Model really is adequate for the preservation of ancestral lore in a digital format. We hope too to analyze if the technological design of the entire platform is relevant to the cultural logic of the natives and appropriate for the young to participate in creating the content. 
Overall we hope the proposition really is helpful to promote ancestral knowledge.

\section{Conclusions}

Creating original and innovative proposals using TIC to preserve ancestral lore is a necessity that arises from the rapid loss of knowledge and the growing technological developments. It is however somewhat paradoxical that this happens in a moment in our history where information and knowledge are the key components and, according to UNESCO [19], it is all thanks to diversity and the freedom of speech they possess.

There are a number of ways to apply TIC, however in this work we consider aspects like the $\mathrm{PNM}$, which give is it the original approach, along with the participation of the indigenous community. The inclusion of indigenous people to the digital era has to do with them being the intellectual creators of all the content and not just as users. The idea for young members of the community to be a part of this also has to do with them making the VC theirs.

One of the main challenges this study faces is the implementation of the Pedagogical Native Model. This means that the activities sought for the recovery of ancestral botanical knowledge have to be designed accordingly to the four dimensions of PNM and the values of the specific community.

The exploratory research and test showed interest of the elders of the community to preserve their knowledge regarding plants and their medicinal uses and it has in no way made them any less keen to use a lot of technology. In Teopantlán, like in most communities, both indigenous and non-indigenous, every day there seems to be less interaction between young members and the elders, and it is a goal of this project to have the elders relate to the younger members of their own community who will in turn preserve the ancestral wisdom.

We trust that between the interactive forums open for debate and discussion, and the exchange of ancestral wisdom about medicinal plant, together with the bilingual database, some interest can be found by members of the community so the VC can become a living space of preservation and spreading of ancestral lore.

The distance we have moved from the beginning of the project has taught us that through collective work between investigators, and member of the community, the technological tools are important but even more so the methodology that follows.

\section{References}

[1] CDI, Consulta sobre mecanismos para la protección de los conocimientos tradicionales, expresiones culturales, recursos naturales, biológicos y genéticos de los pueblos indígenas. 2011.
[2] T. Efferth, "Perspectives for Globalized Natural Medicines," Chin. J. Nat. Med., vol. 9, no. 1, pp. 1-6, 2011.

[3] H. Winschiers-Theophilus, K. Rodil, T. Zaman, A. Yeo, and K. Jensen, "Mobile technologies for preservation of indigenous knowledge in rural communities," in Information Technology in Asia (CITA), 2013 8th International Conference on, 2013, pp. 1-4.

[4] L. Reitsma, A. Smith, and E. van den Hoven, "StoryBeads: Preserving Indigenous Knowledge through Tangible Interaction Design," in 2013 International Conference on Culture and Computing, 2013, pp. 79-85.

[5] H. Winschiers-Theophilus, N. J. Bidwell, S. ChivunoKuria, and G. K. Kapuire, "Determining requirements within an indigenous knowledge system of African rural communities," in Proceedings of the 2010 Annual Research Conference of the South African Institute of Computer Scientists and Information Technologists on SAICSIT '10, 2010, no. 1, pp. 332-340.

[6] T. . Zaman and A. W. . Yeo, "Augmenting indigenous knowledge management with information and communication technology," Int. J. Serv. Technol. Manag., vol. 19, no. 1-3, pp. 137-148, 2013.

[7] N. J. Bidwell, H. Winschiers-Theophilus, G. KochKapuire, and S. Chivuno-Kuria, "Situated interactions between audiovisual media and African herbal lore," Pers. Ubiquitous Comput., vol. 15, no. 6, pp. 609-627, 2011.

[8] C. Brenes Granados, "Multimedia como estrategia para la introducción de TIC en las comunidades indígenas Cabécares de Chirripó," InterSedes, vol. 13, no. 25, pp. 68-81, 2012.

[9] L. Slavsky, "TIC' s para jóvenes indígenas: una experiencia mapuche en la creación colectiva de contenidos culturales digitales," Quinto Sol, vol. 11, pp. 143-166, 2007.

[10] P. Altimiras, J., Peral, D., Vallejo, J., Martín, M. y Roura, "La transmisión de la medicina popular en la Baja Extremadura," Rev. Estud. Extremenos, vol. 65, no. 3, pp. 1547-1587, 2009.

[11] B. Benz, J. Cevallos E., F. Santana M., J. Rosales A., and S. Graf, "Losing Knowledge about Plant Use in the Sierra de Manantlan Biosphere Reserve, Mexico," Econ. Bot., vol. 54, no. 2, pp. 183-191, 2000.

[12] L. Rodríguez, "De enfermedades y remedios: la transmisión oral del uso doméstico de plantas con fines medicinales en Campeche, México.," Apuntes, vol. 25, pp. 62-71, 2012.

[13] CDI, Consulta a Los Pueblos Indigenas Sobre Sus Formas Y Aspiracipones De Desarrollo. 2004.

[14] CDI, Informe general de la Consulta sobre Alcoholismo y Pueblos Indígenas. 2008.

[15] Comité Estatal de Información Estadística y Geográfica del Estado de Puebla (COTEIGEP), Puebla, 
México, 2015 [Online]. Available: http://www.coteig ep.p uebla.gob.mx. [Accessed: 14-Feb-2015].

[16] B. Maldonado, Autonomía y Comunalidad India. Enfoques y propuestas desde Oaxaca. Oaxaca: Centro INAH Oaxaca Secretaría de Asuntos Indígenas del Gobierno del Estado Coalición de Maestros y Promotores Indígenas de Oaxaca Centro de Encuentros y Diálogos Interculturales, 2002.

[17] E. Cházaro, Integración del Modelo Pedagógico basado en la Sabiduria Nativa, cerrando el círculo de aprendizaje. Volúmen II. México: Benemérita Universidad Autónoma de Puebla, 2014.

[18] S. I. Medellin Urquiaga and E. Huerta Velázquez, "La Promoción de las TIC para el Desarrollo en Pueblos Indígenas: Extensión o Comunicación," J. Community Informatics, vol. 3, no. 3, 2007.

[19] UNESCO, Hacia las sociedades del conocimiento. París: Ediciones UNESCO, 2005.

\section{Acknowledgements}

The authors wish to provide acknowledgments to the inhabitants of Teopantlan who kindly participated in the botanical indigenous knowledge instrument piloting process. The authors also wish to thank Emiliano de Vries for the Spanish to English translation of this paper. 